\title{
Impact of Dysmenorrhea and Health-Seeking Behavior among Female Adolescents
}

\author{
Erni Gustina, Sitti Nur Djannah \\ Department of Public Health Science, Faculty of Public Health, Universitas Ahmad Dahlan, Yogyakarta
}

\begin{tabular}{l} 
Article Info \\
\hline Article history: \\
Received Feb 26, 2017 \\
Revised Apr 30, 2017 \\
Accepted May 15, 2017 \\
\hline
\end{tabular}

Keywords:

Adolescents

Attitude

Dysmenorrhea

Health-Seeking Behavior

\begin{abstract}
Dysmenorrhea is one of common health problems to occur during menstrual period and influences women life quality. The aim of the study is to know the effect of dysmenorrhea and health-seeking behavior to teenage girl. This study belongs to observation analytic using cross sectional design. The sample is girls, which is as many as 188 , at the age of 15 to 19 . The data are taken through questionnaire containing several questions, such as age of the respondents, age of menarche, effect dysmenorrhea, attitude on dysmenorrhea, and health-seeking behavior. Bivariate analysis is used Chi Square test. The Prevalence of dysmenorrhea is $68.8 \%$. The effect of dysmenorrhea to girls include the absence from school (9.6\%), sleep disorders $(25 \%)$, decreased appetite $(25.5 \%)$, inability to do exercise $(19.7 \%)$, and daily activity disruptions (9.6\%). There was relationship between the attitude on dysmenorrhea and health-seeking behavior of female adolescents $(\mathrm{p}=0.029)$. Adolescents with positive attitude about menstrual problems will develop good health-seeking behavior during menstrual period compared to those who have negative attitude. The needs to design reproduction health program as well as updating the information to create girls awareness on their health management during dysmenorrhea are necessary.
\end{abstract}

Copyright $\odot 2017$ Institute of Advanced Engineering and Science. All rights reserved.

\section{Corresponding Author:}

Erni Gustina,

Department of Public Health, Universitas Ahmad Dahlan,

Jl. Dr. Soepomo, S.H, Janturan, Yogyakarta. Email: erni.gustina@ikm.uad.ac.id

\section{INTRODUCTION}

Menarche is a unique experience in the maturation of female reproduction organ. Menstrual cycle is one of key indicators of reproduction health function [1]. Menstruation in adolescent is frequently related to the menstrual problems and poor treatment. Irregular menstrual cycle, Pre-Menstrual Syndrome (PMS), and excessive menstrual bleeding are problems of menstruation that influence female reproduction health and fertility [1].

Dysmenorrhea is common menstrual problem. The prevalence of dysmenorrhea and Pre-Menstrual Syndrome in adolescence is varied. It is estimated to be between $16 \%-91 \%$ in active women of reproductive age with severe pain ranged between 2-29\% [2]. A study in Australia reported that the proportion of female adolescents experiencing severe menstrual pain is as much as 93\% [3]. A Research reported that as much as $71.8 \%$ of girls have menstrual problems related to menstrual cycle, $61 \%$ of dysmenorrhea, and $55.8 \%$ of PMS. Most students claimed to experience dysmenorrhea (84.9\%) [4]. 77.8\% of students reported to have menstrual pain starting from the first day of the period; irregular menstrual cycle $(27.2 \%)$, oligo menorrhea $(15.1 \%)[5]$.

Dysmenorrhea in female adolescents significantly influences their academic performance and social roles. Adolescents experiencing menstrual problems tend to be absent from schools, decline their learning concentration and academic performance, be disrupted on their daily activities, and limit their social activities 
[6]-[9]. A research reported is stated that girls with dysmenorrheal symptoms have higher risk to decrease their activities, experience hip strain, back pain, headache, and fatigue [5].

The findings study show that dysmenorrhea is related to students lifestyle, leading to disrupt their daily activities and causing them to be absent from school [10]. Health education should be provided by teachers to help the student with dysmenorrhea. This way, the students can treat themselves and overcome any problems related to dysmenorrhea. The finding study also states that dysmenorrhea is included in gynecological problem and often occurs to teenage girl. In spite of that, health-seeking related to dysmenorrhea is still low [5].

\section{RESEARCH METHOD}

This research belongs to observational analysis applying cross sectional design. The sample is female adolescents at the age of 15-19 years. Inclusive criteria of this research are female adolescents who have reached menarche and experience menstrual problem. 188 respondents become the sample, taken using purposive sampling technique. The data is obtained through questionnaire containing several questions about respondent age, menarche age, dysmenorrhea effect, attitude towards dysmenorrhea, and health-seeking behavior for dysmenorrhea. The data are analyzed using univariate analysis to describe the variables of the research and bivariate analysis to know the relation between independent variables and dependent variables using chi square test.

\section{RESULTS AND ANALYSIS}

\subsection{Result}

The results of this study are obtained from 188 respondents through questionnaire. The average age of the sample is $16.93(\mathrm{SD}=0.67)$. Average menarche age of the sample is $12.10(\mathrm{SD}=0.95)$. The results can be seen in Table 1.

Table 1. Respondents' Characteristic based on Age and Menarche

\begin{tabular}{ccc}
\hline Characteristics & Mean & SD \\
\hline Respondents' age & 16.93 & 0.67 \\
Menarche & 12.10 & 0.95 \\
\hline
\end{tabular}

From 188 respondents, the number of adolescents with normal menstrual cycle, which is 21-35 days, reaches $83.5 \%$, with menstrual period of 3-7 days (92\%). The number of adolescents with dysmenorrhea is 130 respondents $(68.8 \%)$. The data can be seen in Table 2 .

Table 2. Distribution of Frequencies Experienced during Menstrual Period among Female Adolescents

\begin{tabular}{ccc}
\hline Characteristics & Frequency & $\%$ \\
\hline Menstrual cycle & & \\
$<21$ days & 21 & 11.2 \\
$21-35$ days & 157 & 83.5 \\
$>35$ days & 10 & 5.3 \\
Menstrual period & & \\
3-7 days & 15 & 8.0 \\
$>7$ days & 173 & 92.0 \\
Dysmenorrhea & & \\
Yes & 130 & 68.8 \\
No & 58 & 30.7 \\
\hline
\end{tabular}

Table 3 shows the number of adolescents with dysmenorrhea who tend to be absent from school is up to 18 respondents $(9.6 \%)$, sleep disorders up to 47 respondents $(25 \%)$, loss of appetites to 48 respondents $(25.5 \%)$, disrupted from physical exercises to 37 respondents $(19.7 \%)$, and disrupted in their daily activities up to 18 respondents $(9.6 \%)$. 
Table 3. Effects of Dysmenorrhea among Female Adolescents

\begin{tabular}{ccc}
\hline Effect & Frequency & $\%$ \\
\hline Absent from School & & \\
Yes & 18 & 9.6 \\
No & 170 & 90.4 \\
Sleep Disorders & & \\
Yes & 47 & 25 \\
No & 141 & 75 \\
Decreasing Appetite & & \\
Yes & 48 & 25.5 \\
No & 140 & 74.5 \\
Limited physical exercises & & \\
Yes & 37 & 19.7 \\
No & 151 & 80.3 \\
Disrupted social activities & & \\
Yes & 18 & 9.6 \\
No & 170 & 90.4 \\
\hline & & \\
\hline
\end{tabular}

Various services of medication are initiated by female adolescents with dysmenorrhea. From 188 respondents who filled out the questionnaire, $39(20.7 \%)$ go to hospital, $21(11.2 \%)$ to community health center, $17(9.0 \%)$ to private physician, and $8(4.3 \%)$ to private midwife. In terms of medication, $68(36.2 \%)$ respondents take herbal tonic (jamu-pent) to reduce dysmenorrhea pains, $12(6.4 \%)$ take medicine from nearby stores, $30(16 \%)$ apply warm compresses to reduce the pain and $73(38.8 \%)$ respondents only take a rest. The results can be seen in Table 4 .

Table 4. Health-Seeking Behavior among Female Adolescents

\begin{tabular}{ccc}
\hline Health-Seeking Behavior & Frequency & $\%$ \\
\hline Hospitals & 39 & 20.7 \\
Yes & 149 & 79.3 \\
No & & \\
Community Health Center & 21 & 11.2 \\
Yes & 167 & 88.8 \\
No & 17 & 9.0 \\
Private Physician & 171 & 91.0 \\
Yes & & \\
No & 8 & 4.3 \\
Private Midwife & 180 & 95.7 \\
Yes & & \\
No & 68 & 36.2 \\
Taking Herbal Tonic & 120 & 63.8 \\
Yes & & \\
No & 12 & 6.4 \\
Yes & 176 & 93.6 \\
No & & \\
Taking medicines from nearby stores & 30 & 16 \\
Yes & 158 & 84 \\
No & & \\
Applying Warm Compresses & 73 & 38.8 \\
Taking a rest & 115 & 61.2 \\
Yes & & \\
No &
\end{tabular}

Table 5 shows that there was relationship between attitude and health seeking behavior of menstrual disorders in female adolescents $(\mathrm{p}=0.029) \mathrm{RP}=1.232$ (CI 95\%=1.04-1.47). It means that adolescents with negative feelings have 1.232 chances to seek health to non-medical for their menstrual problems, compared to those who have good attitude.

Table 5. Relationship between Attitude and Health-Seeking Behavior among Female Adolescents

\begin{tabular}{ccccc}
\hline \multicolumn{5}{c}{ Health-seeking behaviour } \\
Variable & $\begin{array}{c}\text { Non-medical } \\
(\%)\end{array}$ & $\begin{array}{c}\text { Medical } \\
(\%)\end{array}$ & P & RP (CI 95\%) \\
\hline $\begin{array}{c}\text { Attitude } \\
\text { Negative }\end{array}$ & $72(80.9)$ & $17(19.1)$ & 0.029 & $1.232(1.04-1.47)$ \\
Positive & $65(65.7)$ & $34(34.4)$ & & \\
\hline
\end{tabular}




\subsection{Analysis}

Adolescents are critical period in which several developments occur, such as puberty. Menarche and dysmenorrhea are considered to be important process. Dysmenorrhea or menstrual pains is defined as chronic pain occurs in teenage girl. They found difficulties because of limited information on menstruation and dysmenorrhea. Dysmenorrhea is common gynecological problem happens in women and is defined as cramps in the lower abdomen before or during the menstrual period. Prevalence of dysmenorrhea found in this study is $68.8 \%$. The level of dysmenorrhea in teenage girl is varied. The research in Sri Lanka reported that the dysmenorrhea prevalence is as much as in Sri Lanka 84\% [1], in India 70.2\% [6], in Nigeria 78.1\% [7], in Karachi 78\% [8], in Oman 94\% [11], in Isfahan (Iran) 89.1\% [12], prevalence of dysmenorrhea and premenstrual syndrome were $85.1 \%$ and $72.8 \%$ [13]. Even if dysmenorrhea cannot be clearly seen, it has several implications to the life quality and the health of the community.

Dysmenorrhea also brings negative impact among female adolescents. For example absence from school, sleep disorders, loss of appetite, limited physical exercises, and disrupted social activities. The results of the study is supported by other researches, reporting that dysmenorrhea in female adolescents have significant effect in declining academic achievement, tendency to be absent from school, limitation of physical activities, social withdrawal, limitation of exercises, limitation in performing household activities [7],[8],[11],[14]-[16]. A study conducted by [14] found that there is significant relation between dysmenorrhea and absence from school. Another research [17] reported that there is a requirement to provide health education at school about menstrual problems which involves adolescents and their parents. It is also necessary to do screening test regularly which is aided by the health care providers to prevent absences from school.

Dysmenorrhea is menstrual pain that may influence the life quality of female adolescents. However, only few of them seek health and most of them ignore the pains caused by dysmenorrhea. It is in line with other research, which states that many adolescents are not eager to consult health care providers related to menstrual problems [7],[11]. Dysmenorrhea is seen as normal condition by health workers, adolescents, and parents. It leads to adolescents' doubt to seek medical help. A study reported that despite of its high prevalence and huge impact on the sufferers' life, $76.1 \%$ respondents believes that Dysmenorrhea is normal part of menstrual cycle and only $14.8 \%$ of them seek medical treatment [9]. Study [18] also reported that only $15 \%$ of adolescents with menstrual problems consult a doctor to reduce their pain. It is related the belief passed from generation to generation that women has to bear the burden although it affects their health.

The study also found that adolescents take several treatments, such as consuming herbal tonic, taking medicines from nearby stores, applying warm compresses and taking rest (See Table 3). Dysmenorrhea is menstrual problem that commonly occurs to girl in Oman and only 3\% of them consult the doctor, $21 \%$ take self-medication, $55 \%$ do not take any medication. Common medicines being consumed are paracetamol (16\%), ibuprofen (29.8\%), and mefenamic acid (12.3\%) [11].The results of the study show that there was a relationship between attitude and health-seeking behavior for menstrual problems in girls (See Table 5). Individual ability to seek reproduction health care or self-treatment of dysmenorrhea is based on their knowledge about the condition. Sufficient information about dysmenorrhea may influence women's attitude towards dysmenorrhea. Even though it occurs in adolescents, they develop negative attitude towards it. They are reluctant to seek health to reduce their menstrual problems because they feel embarrassed to communicate it with others. They think that dysmenorrhea is part of menstrual cycle and it is not necessary for them to seek help. Adolescents tend to take self-medication, such as buying pain killers in nearby stores.

Attitude is a readiness or willingness to act and is not an implication of particular motives. Attitude is a predisposition to act positively or negatively towards particular object that influence their behavior and relations with others. Negative attitude towards menstrual problems become the obstacle in health-seeking practice [19]. One of the factors causing an individual to seek health is the severity of the illness, such as the probability of causing death or paralysis. Besides, it may lead to social impact, such as to jobs, family life, and social relations [20].

The results of this study are corresponding to other research which states that majority of the participants have negative attitude towards dysmenorrhea [7]. A Study reported that psycho socio cultural factors, such as personal tendency and social cultural background determine the way an individual communicate the pains to others [21]. A study suggested that adolescents do not seek medical treatments because they feel embarrassed to discuss menstrual problems with others [1]. A study reported that anxiety towards embarrassing question is the key factor influencing adolescents' decision to seek medical treatment in relation to menstrual problems in China [19].

In determining the attitude, there are several important components. Those are knowledge, awareness, mindset, beliefs, and emotion. An attitude is not automatically actualized in a behavior. To improve female adolescents' awareness; intervention that is targeted to improve awareness and family health 
education is provision to all women [22]. Female adolescents should be educated to identify their own needs on seeking professional health care in case they suffer from dysmenorrhea.

\section{CONCLUSION}

There was a relationship between attitude and health-seeking behavior of female adolescents. Those with positive attitude will develop good health-seeking behavior to overcome menstrual problem compared to those with negative attitude. Designing reproduction health program and updating information in order to raise female adolescent awareness on health management during dysmenorrhea.

\section{REFERENCES}

[1] Wijesiri H. S. M. S. K. and Suresh. T. S., "Knowledge and attitudes towards dysmenorrhea among adolescent girls in an urban school in Sri Lanka," Nursing and Health Sciences, vol/issue: 15(1), pp. 58-64, 2013.

[2] H. Ju, et al., "The prevalence and risk factors of dysmenorrhea," Epidemiologic Rev, vol. 36, pp. 104-113, 2013.

[3] M. A. Parker, et al., "The menstrual disorder of teenagers (MDOT) study: determining typical menstrual patterns and menstrual disturbance in a large population based study of Australian teenagers," International Journal of Obstetrics and Gynecology, vol/issue: 11(7), pp. 185-192, 2010.

[4] S. B. Thakre, et al., "Urban-Rural Differences in Menstrual Problems and Practices of Girl Students in Nagpur, India,” Indian Pedistrics, vol. 49, pp. 733-736, 2012.

[5] M. Seven, et al., "Evaluating Dysmenorrhea i a Sample of Turkish Nursing Students," Pain Management Nursing, vol/issue: 15(3), pp. 664-671, 2014.

[6] S. Omidvar, et al., "Primary Dysmenorrhea and Menstrual Symptoms in Indian Female Students: Prevalence, Impact and Management," Global Journal of Health Science, vol/issue: 8(8), pp. 135-144, 2016.

[7] A. A. Farotimi, et al., "Knowledge, Attitude, and Healthcare-Seeking Behavior Towards Dysmenorrhea among Female Students of a Private University in Ogun State, Nigeria," Journal of Basic and Clinical Reproductive Sciences, vol/issue: 4(1), pp. 33-38, 2015.

[8] S. Gulzar, et al., "Prevalence, Perceptions and Effects of Dysmenorrhea in School Going Female Adolescents of Karachi, Pakistan, "International Journal of Innovative Research \& Development, vol/issue: 4(2), pp. 236-240, 2015.

[9] Wong L. P. and E. M. Khoo, "Dysmenorrhea in a multiethnic population of adolescent Asian girls," International Journal Gynecology Obstetric, vol. 108, pp. 139-42, 2010.

[10] M. Kazama, et al., "Prevalence of Dysmenorrhea and Its Correlating Lifestyle Factors in Japanese Female Junior High School Students,” Tohoku J. Exp. Med, vol/issue: 236(2), pp. 107-113, 2015.

[11] R. Al-Kindi and A. Al-Bulushi, "Prevalence and Impact of Dysmenorrhea among Omani High School Students," SQU Medical Journal. Vol/issue: 11(4), pp. 485-491, 2011.

[12] N. Habibi, et al., "Prevalence of Primary Dysmenorrhea and Factors Associated with Its Intensity among Undergraduate Students: A Cross-Sectional Study,” Pain Management Nursing, vol/issue: 16(6), pp. 855-861, 2015.

[13] M. L. Shiferaw, et al., "Menstrual problems and associated factors among students of Bahir Dar University, Amhara National Regional State, Ethiopia: A cross-sectional survey," The Pan African Medical Journal, vol/issue: 17(246), 2014

[14] A. E. Olowokere, et al., "Menstrual disorders: The implications on health and academic activities of female undergraduates in a Federal university in Nigeria," Journal of Nursing Education and Practice, vol/issue: 4(4_, pp. 126-35, 2014.

[15] Ruhi D. and Meenal K., "Prevalance of Dysmenorrhea among Girsl Students in a Medical College," PJMS, vol/issue: 4(1), pp. 49-51, 2014.

[16] Oni T. H. and T. G. Tshitangano, "Prevalence of Menstrual Disorders and its Academic Impact amongst Tshivenda Speaking Teenagers in Rural South Africa,” J Hum Ecol, vol/issue: 51(12), pp. 214-219, 2015.

[17] D. G. Dambhare, et al., "Age at menarche and menstrual cycle pattern among school adolescent girls in Central India," Global journal of health science, vol/issue: 4(1), pp. 105-111, 2012.

[18] C. Sultan, et al.., “Adolescent dysmenorrhea," Endocr Dev, vol. 22, pp. 171-180, 2012.

[19] S. S. C. Chan, et al., "Menstrual problems and health-seeking behavior in Hong Kong Chinese girls," Hong Kong Medical Journal, vol/issue: 15(1), pp. 18-23, 2012.

[20] K. Glanz, "Health behavior and health Education: Theory, Research and Practice," 4TH Edition, San Fransisco, Jossey-Bass, 2008. 
[21] Azaito L. and O. Adejumo, "An ethnographic exploration of post-operative pain experiences among Ghanaian surgical patients," Journal of Transcultural Nursing, vol. 8, pp. 1-7, 2014.

[22] D. Sapkota, et al., "Knowledge and practices regarding menstrual among school going adolescents of rural Nepal," Original Article Journal of Kathmandu Medical College, vol/issue: 2(3), pp. 2-8, 2013. 